\title{
On Rate of Convergence of Jungck-Type Iterative Schemes
}

\author{
Nawab Hussain, ${ }^{1}$ Vivek Kumar, ${ }^{2}$ and Marwan A. Kutbi ${ }^{1}$ \\ ${ }^{1}$ Department of Mathematics, King Abdulaziz University, P.O. Box 80203, Jeddah 21589, Saudi Arabia \\ ${ }^{2}$ Department of Mathematics, M.D. University, Rohtak 124001, India
}

Correspondence should be addressed to Vivek Kumar; ratheevivek15@yahoo.com

Received 27 February 2013; Accepted 3 April 2013

Academic Editor: Yisheng Song

Copyright (C) 2013 Nawab Hussain et al. This is an open access article distributed under the Creative Commons Attribution License, which permits unrestricted use, distribution, and reproduction in any medium, provided the original work is properly cited.

We introduce a new iterative scheme called Jungck-CR iterative scheme and study the stability and strong convergence of this iterative scheme for a pair of nonself-mappings using a certain contractive condition. Also, convergence speed comparison and applications of Jungck-type iterative schemes will be shown through examples.

\section{Introduction and Preliminaries}

Let $X$ be a Banach space, $Y$ an arbitrary set, and $S, T: Y \rightarrow X$ such that $T(Y) \subseteq S(Y)$. For $x_{0} \in Y$, consider the following iterative scheme:

$$
S x_{n+1}=T x_{n}, \quad n=0,1, \ldots
$$

This scheme is called Jungck iterative scheme and was essentially introduced by Jungck [1] in 1976 and it becomes the Picard iterative scheme when $S=I_{d}$ (identity mapping) and $Y=X$.

For $\alpha_{n} \in[0,1]$, Singh et al. [2] defined the Jungck-Mann iterative scheme as

$$
S x_{n+1}=\left(1-\alpha_{n}\right) S x_{n}+\alpha_{n} T x_{n} .
$$

For $\alpha_{n}, \beta_{n}, \gamma_{n} \in[0,1]$, Olatinwo defined the Jungck-Ishikawa [3] (see also [4, 5]) and Jungck-Noor [6] iterative schemes as

$$
\begin{aligned}
& S x_{n+1}=\left(1-\alpha_{n}\right) S x_{n}+\alpha_{n} T y_{n}, \\
& S y_{n}=\left(1-\beta_{n}\right) S x_{n}+\beta_{n} T x_{n}, \\
& S x_{n+1}=\left(1-\alpha_{n}\right) S x_{n}+\alpha_{n} T y_{n}, \\
& S y_{n}=\left(1-\beta_{n}\right) S x_{n}+\beta_{n} T z_{n}, \\
& S z_{n}=\left(1-\gamma_{n}\right) S x_{n}+\gamma_{n} T x_{n},
\end{aligned}
$$

respectively.
Chugh and Kumar [7] defined the Jungck-SP iterative scheme as

$$
\begin{aligned}
& S x_{n+1}=\left(1-\alpha_{n}\right) S y_{n}+\alpha_{n} T y_{n}, \\
& S y_{n}=\left(1-\beta_{n}\right) S z_{n}+\beta_{n} T z_{n}, \\
& S z_{n}=\left(1-\gamma_{n}\right) S x_{n}+\gamma_{n} T x_{n},
\end{aligned}
$$

where $\left\{\alpha_{n}\right\},\left\{\beta_{n}\right\}$, and $\left\{\gamma_{n}\right\}$ are sequences of positive numbers in $[0,1]$.

Remark 1. If $X=Y$ and $S=I_{d}$ (identity mapping), then the Jungck-SP (5), Jungck-Noor (4), Jungck-Ishikawa (3), and the Jungck-Mann (2) iterative schemes, respectively, become the SP [8], Noor [9], Ishikawa [10] and the Mann [11] iterative schemes.

Jungck [1] used the iterative scheme (1) to approximate the common fixed points of the mappings $S$ and $T$ satisfying the following Jungck contraction:

$$
d(T x, T y) \leq \alpha d(S x, S y), \quad 0 \leq \alpha<1 .
$$

Olatinwo [3] used the following more general contractive definition than (6) to prove the stability and strong convergence results for the Jungck-Ishikawa iteration process: there exists a real number $a \in[0,1)$ and a monotone increasing function $\phi: R^{+} \rightarrow R^{+}$such that $\phi(0)=0$ and for all $x, y \in Y$, we have

$$
\|T x-T y\| \leq \phi(\|S x-T x\|)+a\|S x-S y\| .
$$


Olatinwo [6] used the convergences of Jungck-Noor iterative scheme (4) to approximate the coincidence points (not common fixed points) of some pairs of generalized contractivelike operators with the assumption that one of each of the pairs of maps is injective.

Motivated by the above facts, for $\alpha_{n}, \beta_{n}$, and $\gamma_{n} \in[0,1]$, we introduce the following iterative scheme:

$$
\begin{gathered}
S x_{n+1}=\left(1-\alpha_{n}\right) S y_{n}+\alpha_{n} T y_{n} \\
S y_{n}=\left(1-\beta_{n}\right) T x_{n}+\beta_{n} T z_{n} \\
S z_{n}=\left(1-\gamma_{n}\right) S x_{n}+\gamma_{n} T x_{n}
\end{gathered}
$$

and call it Jungck-CR iterative scheme.

Remark 2. Putting $\alpha_{n}=0$ and $\alpha_{n}=0, \beta_{n}=1$ in Jungck-CR iterative scheme, we get Jungck versions of Agarwal et al. [12] and Sahu and Petruşel [13] iterative schemes, respectively, as defined below:

$$
\begin{gathered}
S x_{n+1}=\left(1-\beta_{n}\right) T x_{n}+\beta_{n} T y_{n}, \\
S y_{n}=\left(1-\gamma_{n}\right) S x_{n}+\gamma_{n} T x_{n}, \\
S x_{n+1}=T y_{n}, \\
S y_{n}=\left(1-\gamma_{n}\right) S x_{n}+\gamma_{n} T x_{n} .
\end{gathered}
$$

We will need the following definitions and lemma.

Definition 3 (see [14]). Let $\left\{u_{n}\right\}$ and $\left\{v_{n}\right\}$ be two fixed-point iteration procedures that converge to the same fixed point $p$ on a normed space $X$ such that the error estimates

$$
\begin{gathered}
\left\|u_{n}-p\right\| \leq a_{n}, \\
\left\|v_{n}-p\right\| \leq b_{n}
\end{gathered}
$$

are available, where $\left\{a_{n}\right\}$ and $\left\{b_{n}\right\}$ are two sequences of positive numbers (converging to zero). If $\left\{a_{n}\right\}$ converge faster than $\left\{b_{n}\right\}$, then we say that $\left\{u_{n}\right\}$ converges faster to $p$ than $\left\{v_{n}\right\}$.

Definition 4 (see [15]). Suppose that $\left\{a_{n}\right\}$ and $\left\{b_{n}\right\}$ are two real convergent sequences with limits $a$ and $b$, respectively. Then, $\left\{a_{n}\right\}$ is said to converge faster than $\left\{b_{n}\right\}$ if

$$
\lim _{n \rightarrow \infty}\left|\frac{a_{n}-a}{b_{n}-b}\right|=0 .
$$

Definition 5 (see $[16,17]$ ). Let $f$ and $g$ be two self-maps on $X$. A point $x$ in $X$ is called (1) a fixed point of $f$ if $f(x)=x$; (2) coincidence point of a pair $(f, g)$ if $f x=g x$; (3) common fixed point of a pair $(f, g)$ if $x=f x=g x$. If $w=f x=g x$ for some $x$ in $X$, then $w$ is called a point of coincidence of $f$ and $g$. A pair $(f, g)$ is said to be weakly compatible if $f$ and $g$ commute at their coincidence points.

Lemma 6 (see [18]). If $\delta$ is a real number such that $0 \leq$ $\delta<1$ and $\left\{\epsilon_{n}\right\}_{n=0}^{\infty}$ is a sequence of positive numbers such that $\lim _{n \rightarrow \infty} \epsilon_{n}=0$, then for any sequence of positive numbers $\left\{u_{n}\right\}_{n=0}^{\infty}$ satisfying

$$
u_{n+1} \leq \delta u_{n}+\epsilon_{n}, \quad n=0,1,2, \ldots
$$

one has $\lim _{n \rightarrow \infty} u_{n}=0$.
Definition 7 (see [2]). Let $S, T: Y \rightarrow X$ be non-selfoperators for an arbitrary set $Y$ such that $T(Y) \subseteq S(Y)$ and $p$ a point of coincidence of $S$ and $T$. Let $\left\{S x_{n}\right\}_{n=0}^{\infty} \subset X$, be the sequence generated by an iterative procedure

$$
S x_{n+1}=f\left(T, x_{n}\right), \quad n=0,1 \ldots,
$$

where $x_{0} \in X$ is the initial approximation and $f$ is some function. Suppose that $\left\{S x_{n}\right\}_{n=0}^{\infty}$ converges to $p$. Let $\left\{S y_{n}\right\}_{n=0}^{\infty} \subset X$ be an arbitrary sequence and set $\varepsilon_{n}=d\left(S y_{n}, f\left(T, y_{n}\right)\right), n=$ $0,1, \ldots$. Then, the iterative procedure (11) is said to be $(S, T)$ stable or stable if and only if $\lim _{n \rightarrow \infty} \epsilon_{n}=0$ implies $\lim _{n \rightarrow \infty} S y_{n}=p$.

The purpose of this paper is to study the stability and strong convergence of Jungck-CR (JCR) iterative scheme for nonself-mappings in an arbitrary Banach space by employing the contractive conditions (7) and then to compare convergence rates of Jungck-type iterative schemes. Moreover, applications of Jungck-type iterative schemes in recurrent neural networks (RNN) analysis will be discussed.

\section{Strong Convergence in an Arbitrary Banach Space}

Theorem 8. Let $(X,\|\cdot\|)$ be an arbitrary Banach space, and let $S, T: Y \rightarrow X$ be nonself-operators on an arbitrary set $Y$ satisfying contractive condition (7). Assume that $T(Y) \subseteq S(Y)$, $S(Y)$ is a complete subspace of $X$ and $S z=T z=p$ (say). For $x_{0} \in Y$, let $\left\{S x_{n}\right\}_{n=0}^{\infty}$ be the Jungck-CR iterative scheme defined by (JCR), where $\left\{\alpha_{n}\right\},\left\{\beta_{n}\right\},\left\{\gamma_{n}\right\}$ are sequences of positive numbers in $[0,1]$ with $\left\{\alpha_{n}\right\}$ satisfying $\sum_{n=0}^{\infty} \alpha_{n}=\infty$. Then, the Jungck-CR iterative scheme $\left\{S x_{n}\right\}_{n=0}^{\infty}$ converges strongly to $p$. Also, $p$ will be the unique common fixed point of $S, T$ provided that $Y=X$, and $S$ and $T$ are weakly compatible.

Proof. First, we prove that Jungck-CR iterative scheme $\left\{S x_{n}\right\}_{n=0}^{\infty}$ converges strongly to $p$.

It follows from (JCR) and (7) that

$$
\begin{aligned}
\left\|S x_{n+1}-p\right\|= & \left\|\left(1-\alpha_{n}\right) S y_{n}+\alpha_{n} T y_{n}-\left(1-\alpha_{n}+\alpha_{n}\right) p\right\| \\
\leq & \left(1-\alpha_{n}\right)\left\|S y_{n}-p\right\|+\alpha_{n}\left\|T y_{n}-p\right\| \\
= & \left(1-\alpha_{n}\right)\left\|S y_{n}-p\right\|+\alpha_{n}\left\|T z-T y_{n}\right\| \\
\leq & \left(1-\alpha_{n}\right)\left\|S y_{n}-p\right\| \\
& +\alpha_{n}\left\{\phi(\|S z-T z\|)+a\left\|S z-S y_{n}\right\|\right\} \\
= & \left(1-\alpha_{n}\right)\left\|S y_{n}-p\right\|+a \alpha_{n}\left\|S y_{n}-p\right\| \\
= & {\left[1-\alpha_{n}(1-a)\right]\left\|S y_{n}-p\right\| . }
\end{aligned}
$$

Now, we have the following estimates:

$$
\begin{aligned}
\left\|S y_{n}-p\right\|= & \left\|\left(1-\beta_{n}\right) T x_{n}+\beta_{n} T z_{n}-\left(1-\beta_{n}+\beta_{n}\right) p\right\| \\
\leq & \left(1-\beta_{n}\right)\left\|T x_{n}-p\right\|+\beta_{n}\left\|T z_{n}-p\right\| \\
\leq & \left(1-\beta_{n}\right)\left\|T x_{n}-T z\right\|+\beta_{n}\left\|T z_{n}-T z\right\| \\
\leq & \left(1-\beta_{n}\right)\left(\phi(\|S z-T z\|)+a\left\|S x_{n}-S z\right\|\right) \\
& +\beta_{n}\left\{\phi(\|S z-T z\|)+a\left\|S z_{n}-S z\right\|\right\} \\
\leq & \left(1-\beta_{n}\right) a\left\|S x_{n}-p\right\|+\beta_{n} a\left\|S z_{n}-p\right\|,
\end{aligned}
$$




$$
\begin{aligned}
\left\|S z_{n}-p\right\|= & \left\|\left(1-\gamma_{n}\right) S x_{n}+\gamma_{n} T x_{n}-\left(1-\gamma_{n}+\gamma_{n}\right) p\right\| \\
\leq & \left(1-\gamma_{n}\right)\left\|S x_{n}-p\right\|+\gamma_{n}\left\|T x_{n}-T z\right\| \\
\leq & \left(1-\gamma_{n}\right)\left\|S x_{n}-p\right\| \\
& +\gamma_{n}\left\{\phi(\|S z-T z\|)+a\left\|S x_{n}-S z\right\|\right\} \\
= & \left(1-\gamma_{n}(1-a)\right)\left\|S x_{n}-p\right\| .
\end{aligned}
$$

It follows from (13) that

$$
\begin{aligned}
\left\|S y_{n}-p\right\| \leq & \left(1-\beta_{n}\right) a\left\|S x_{n}-p\right\| \\
& +\beta_{n} a\left(1-\gamma_{n}(1-a)\right)\left\|S x_{n}-p\right\| .
\end{aligned}
$$

Using $\left(1-\beta_{n}\right) a \leq\left(1-\beta_{n}\right)$ and $\beta_{n} a\left(1-\gamma_{n}(1-a)\right) \leq \beta_{n} a$, inequality (14) yields

$$
\left\|S y_{n}-p\right\| \leq\left(1-\beta_{n}(1-a)\right)\left\|S x_{n}-p\right\| .
$$

It follows from (15) and (12) that

$$
\begin{aligned}
\left\|S x_{n+1}-p\right\| & \leq\left[1-\alpha_{n}(1-a)\right]\left[1-\beta_{n}(1-a)\right]\left\|S x_{n}-p\right\| \\
& \leq\left[1-\alpha_{n}(1-a)\right]\left\|S x_{n}-p\right\| \\
& \leq \prod_{k=0}^{n}\left[1-\alpha_{k}(1-a)\right]\left\|S x_{0}-p\right\| \\
& \leq e^{-(1-a) \sum_{k=0}^{\infty} \alpha_{k}}\left\|S x_{0}-p\right\| .
\end{aligned}
$$

Since $0 \leq a<1, \alpha_{k} \in[0,1]$ and $\sum_{n=0}^{\infty} \alpha_{n}=\infty$, so $e^{-(1-a) \sum_{k=0}^{n} \alpha_{k}} \rightarrow 0$ as $n \rightarrow \infty$.

Hence, it follows from (16) that $\lim _{n \rightarrow \infty}\left\|S x_{n+1}-p\right\|=0$. Therefore, $\left\{S x_{n}\right\}_{n=0}^{\infty}$ converges strongly to $p$.

Now, we prove that $p$ is unique common fixed point of $S$ and $T$.

Let there exist another point of coincidence say $p^{*}$. Then, there exists $q^{*} \in X$ such that $S q^{*}=T q^{*}=p^{*}$. But from (7), we have

$$
\begin{aligned}
0 & \leq\left\|p-p^{*}\right\|=\left\|T q-T q^{*}\right\| \\
& \leq \phi(\|S q-T q\|)+a\left\|S q-S q^{*}\right\| \\
& =a\left\|p-p^{*}\right\|,
\end{aligned}
$$

which implies that $p=p^{*}$ as $0 \leq a<1$.

Now, as $S$ and $T$ are weakly compatible and $p=T q=S q$, so $T p=T T q=T S q=S T q$ and hence $T p=S p$. Therefore, $T p$ is a point of coincidence of $S, T$ and since the point of coincidence is unique then $p=T p$. Thus, $T p=S p=p$, and therefore $p$ is unique common fixed point of $S$ and $T$.

Corollary 9. Let $(X,\|\cdot\|)$ be an arbitrary Banach space, and, $S, T: Y \rightarrow X$ be nonself-operators on an arbitrary set $Y$ satisfying contractive condition (7). Assume that $T(Y) \subseteq S(Y)$, $S(Y)$ is a complete subspace of $X$ and $S z=T z=p$ (say). For $x_{0} \in Y$, let $\left\{S x_{n}\right\}_{n=0}^{\infty}$ be the iterative scheme defined by $(J A)$, where $\left\{\alpha_{n}\right\},\left\{\beta_{n}\right\}$ are sequences of positive numbers in $[0,1]$ with $\left\{\alpha_{n}\right\}$ satisfying $\sum_{n=0}^{\infty} \alpha_{n}=\infty$. Then the Jungck-Agarwal iterative scheme $\left\{S x_{n}\right\}_{n=0}^{\infty}$ converges strongly to $p$. Also, $p$ will be the unique common fixed point of $S, T$ provided that $Y=X$, and $S$ and $T$ are weakly compatible.

Proof. Putting $\alpha_{n}=0$ and $\beta_{n}=\alpha_{n}$, in iterative scheme (JCR), convergence of iterative scheme (JA) can be proved on the same lines as in Theorem 8.

Corollary 10. Let $(X,\|\cdot\|)$ be an arbitrary Banach space and $S$, and let $T: Y \rightarrow X$ be nonself-operators on an arbitrary set $Y$ satisfying contractive condition (7). Assume that $T(Y) \subseteq S(Y)$, $S(Y)$ is a complete subspace of $X$ and $S z=T z=p$ (say). For $x_{0} \in Y$, let $\left\{S x_{n}\right\}_{n=0}^{\infty}$ be the Jungck-S iterative scheme defined by $(J S)$, where $\left\{\alpha_{n}\right\},\left\{\beta_{n}\right\}$ are sequences of positive numbers in $[0,1]$ with $\left\{\alpha_{n}\right\}$ satisfying $\sum_{n=0}^{\infty} \alpha_{n}=\infty$. Then the Jungck-S iterative scheme $\left\{S x_{n}\right\}_{n=0}^{\infty}$ converges strongly to $p$. Also, $p$ will be the unique common fixed point of $S, T$ provided that $Y=X$, and $S$ and $T$ are weakly compatible.

Proof. Putting $\alpha_{n}=0$ and $\gamma_{n}=\alpha_{n}, \beta_{n}=1$ in iterative scheme (JCR), convergence of iterative scheme (JS) can be proved on the same lines as in the Theorem 8.

The following examples reveal the validity of our results. Example 11. Let $X=Y=[0,1]$. Define $T$ and $S$ by

$$
\begin{gathered}
T(x)=\left\{\begin{array}{cc}
0, & x \in[0,1) \\
\frac{1}{2}, & x=1
\end{array}\right\}, \quad S x=x^{2}, \\
\alpha_{n}=\beta_{n}=\gamma_{n}=\frac{1}{\sqrt{2 n+4}}, \\
\phi(t)=2 a t .
\end{gathered}
$$

It is clear that $T$ and $S$ are quasicontractive operators satisfying (7) but do not satisfy contractive condition (6), with a unique common fixed point 0 .

Using computer programming in $\mathrm{C}++$ with initial approximation $x_{0}=1$, convergence of Jungck-CR iterative scheme to the common fixed point 0 is shown in Table 1.

Example 12. Let $Y=X=[0,1]$. Define $T$ and $S$ by $T(x)=(1 / 2)(1 / 2+x), S(x)=1-x, \alpha_{n}=\beta_{n}=\gamma_{n}=$ $1 / \sqrt{2 n+4}$, and $\phi(t)=2 a t$. It is clear that $T$ and $S$ are weakly compatible quasicontractive operators satisfying (7) with a unique common fixed point 0.5.

Using computer programming in $\mathrm{C}++$ with initial approximation $x_{0}=0.8$, convergence of Jungck-CR iterative scheme to the common fixed point 0.5 is shown in Table 2.

Theorem 13. Let $(X,\|\cdot\|)$ be an arbitrary Banach space and $S$, and let $T: Y \rightarrow X$ be nonself operators on an arbitrary set $Y$ satisfying contractive condition (7). Assume that $T(Y) \subseteq$ $S(Y), S(Y)$ is a complete subspace of $X$, and $S z=T z=p$ (say). For $x_{0} \in Y$ and $\alpha \in(0,1)$, let $\left\{S x_{n}\right\}_{n=0}^{\infty}$ be the Jungck-CR iterative scheme (JCR) converging to $p$, where $\left\{\alpha_{n}\right\},\left\{\beta_{n}\right\},\left\{\gamma_{n}\right\}$ 
TABLE 1

\begin{tabular}{lc}
\hline Number of iterations $(n)$ & Jungck-CR iterative scheme $\left(S x_{n+1}\right)$ \\
\hline 0 & 1 \\
1 & 0.5 \\
2 & 0.125 \\
3 & 0 \\
4 & 0 \\
\hline
\end{tabular}

are sequences in $[0,1]$ with $\left\{\alpha_{n}\right\}$ satisfying $\alpha \leq \alpha_{n}$ for all $n$. Then, the Jungck-CR iterative scheme is $(S, T)$-stable.

Proof. Suppose that $\left\{S y_{n}\right\}_{n=0}^{\infty} \subset X$ be an arbitrary sequence, $\varepsilon_{n}=\left\|S y_{n+1}-\left(1-\alpha_{n}\right) S b_{n}-\alpha_{n} T b_{n}\right\|, n=0,1,2,3 \ldots$, where $S b_{n}=\left(1-\beta_{n}\right) T y_{n}+\beta_{n} T c_{n}, S c_{n}=\left(1-\gamma_{n}\right) S y_{n}+\gamma_{n} T y_{n}$ and let $\lim _{n \rightarrow \infty} \epsilon_{n}=0$.

Then, for Jungck-CR iterative scheme (JCR), we have

$$
\begin{aligned}
\left\|S y_{n+1}-p\right\| \leq & \left\|S y_{n+1}-\left(1-\alpha_{n}\right) S b_{n}-\alpha_{n} T b_{n}\right\| \\
& +\left\|\left(1-\alpha_{n}\right) S b_{n}+\alpha_{n} T b_{n}-\left(1-\alpha_{n}+\alpha_{n}\right) p\right\| \\
\leq & \varepsilon_{n}+\left(1-\alpha_{n}\right)\left\|S b_{n}-p\right\|+\alpha_{n}\left\|T b_{n}-p\right\| \\
= & \varepsilon_{n}+\left(1-\alpha_{n}\right)\left\|S b_{n}-p\right\|+\alpha_{n}\left\|T z-T b_{n}\right\| \\
\leq & \varepsilon_{n}+\left(1-\alpha_{n}\right)\left\|S b_{n}-p\right\| \\
& +\alpha_{n}\left\{\phi(\|S z-T z\|)+a\left\|S z-S b_{n}\right\|\right\} \\
= & \varepsilon_{n}+\left(1-\alpha_{n}\right)\left\|S b_{n}-p\right\| \\
& +\alpha_{n}\left\{\phi(\|0\|)+a\left\|S z-S b_{n}\right\|\right\} \\
= & {\left[1-\alpha_{n}(1-a)\right]\left\|S b_{n}-p\right\|+\varepsilon_{n} . }
\end{aligned}
$$

Now, we have the following estimates:

$$
\begin{aligned}
\left\|S b_{n}-p\right\|= & \left\|\left(1-\beta_{n}\right) T y_{n}+\beta_{n} T c_{n}-\left(1-\beta_{n}+\beta_{n}\right) p\right\| \\
\leq & \left(1-\beta_{n}\right)\left\|T y_{n}-p\right\|+\beta_{n}\left\|T c_{n}-p\right\| \\
= & \left(1-\beta_{n}\right)\left\|T y_{n}-T z\right\|+\beta_{n}\left\|T z-T c_{n}\right\| \\
\leq & \left(1-\beta_{n}\right)\left\{\phi(\|S z-T z\|)+a\left\|S z-S y_{n}\right\|\right\} \\
& +\beta_{n}\left\{\phi(\|S z-T z\|)+a\left\|S z-S c_{n}\right\|\right\} \\
\leq & \left(1-\beta_{n}\right) a\left\|p-S y_{n}\right\|+\beta_{n} a\left\|p-S c_{n}\right\|, \\
\left\|S c_{n}-p\right\|= & \left\|\left(1-\gamma_{n}\right) S y_{n}+\gamma_{n} T y_{n}-\left(1-\gamma_{n}+\gamma_{n}\right) p\right\| \\
\leq & \left(1-\gamma_{n}\right)\left\|S y_{n}-p\right\|+\gamma_{n}\left\|T y_{n}-p\right\| \\
= & \left(1-\gamma_{n}\right)\left\|S y_{n}-p\right\|+\gamma_{n}\left\|T z-T y_{n}\right\| \\
\leq & \left(1-\gamma_{n}\right)\left\|S y_{n}-T z\right\| \\
& +\gamma_{n}\left\{\phi(\|S z-T z\|)+a\left\|S z-S y_{n}\right\|\right\} \\
= & \left(1-\gamma_{n}(1-a)\right)\left\|S y_{n}-p\right\| .
\end{aligned}
$$

TABLE 2

\begin{tabular}{lc}
\hline Number of iterations $(n)$ & Jungck-CR iterative scheme $\left(S x_{n+1}\right)$ \\
\hline 0 & 0.2 \\
1 & 0.523438 \\
2 & 0.496593 \\
3 & 0.50065 \\
4 & 0.499855 \\
5 & 0.500036 \\
6 & 0.49999 \\
7 & 0.500003 \\
8 & 0.499999 \\
9 & $\mathbf{0 . 5}$ \\
10 & $\mathbf{0 . 5}$ \\
\hline
\end{tabular}

It follows from (19), (20) that

$$
\left\|S y_{n+1}-p\right\| \leq\left[1-\alpha_{n}(1-a)\right]\left\|S y_{n}-p\right\|+\varepsilon_{n} .
$$

Using $0<\alpha \leq \alpha_{n}$ and $a \in[0,1)$, we have $\left[1-\alpha_{n}(1-a)\right]<1$.

Hence using Lemma 6, (21) yields $\lim _{n \rightarrow \infty} S y_{n+1}=p$.

Conversely, let $\lim _{n \rightarrow \infty} S y_{n+1}=p$. Then, using contractive condition (7) and the triangle inequality, we have

$$
\begin{aligned}
\varepsilon_{n} & =\left\|S y_{n+1}-\left(1-\alpha_{n}\right) S b_{n}-\alpha_{n} T b_{n}\right\| \\
& \leq\left\|S y_{n+1}-p\right\|+\left\|\left(1-\alpha_{n}+\alpha_{n}\right) p-\left(1-\alpha_{n}\right) S b_{n}-\alpha_{n} T b_{n}\right\| \\
& \leq\left\|S y_{n+1}-p\right\|+\left(1-\alpha_{n}\right)\left\|p-S b_{n}\right\|+\alpha_{n}\left\|p-T b_{n}\right\| \\
& =\left\|S y_{n+1}-p\right\|+\left(1-\alpha_{n}\right)\left\|S b_{n}-p\right\|+\alpha_{n}\left\|T z-T b_{n}\right\| \\
& \leq\left\|S y_{n+1}-p\right\|+\left(1-\alpha_{n}\right)\left\|S b_{n}-p\right\|+a \alpha_{n}\left\|S z-S b_{n}\right\| \\
& =\left\|S y_{n+1}-p\right\|+\left[1-\alpha_{n}(1-a)\right]\left\|S b_{n}-p\right\| .
\end{aligned}
$$

By using estimates (20), (22), yields

$$
\varepsilon_{n} \leq\left[1-\alpha_{n}(1-a)\right]\left\|S y_{n}-p\right\|+\left\|S y_{n+1}-p\right\| .
$$

Hence, $\lim _{n \rightarrow \infty} \varepsilon_{n}=0$.

Therefore, the JCR iterative scheme is $(S, T)$ stable.

\section{Results on Direct Comparison of Jungck- Type Iterative Schemes}

Various authors [7, 13-15, 19-22] have worked on convergence speed of iterative schemes. In [14], Berinde showed that Picard iteration is faster than Mann iteration for quasicontractive operators. In [15], Qing and Rhoades by taking an example showed that Ishikawa iteration is faster than Mann iteration for a certain quasicontractive operator. In [20], Hussain et al. provided an example of a quasicontractive operator for which the iterative scheme due to Agarwal et al. is faster than Mann and Ishikawa iterative schemes. Recently, Chugh and Kumar [19] showed that SP iterative scheme with error terms converges faster than Ishikawa and Noor iterative schemes for accretive-type mappings. For recent work in this direction, we refer the reader to [23-27] and references therein. 
Theorem 14. Let $(X,\|\cdot\|)$ be an arbitrary Banach space, and let $S, T: Y \rightarrow X$ be nonself-operators on an arbitrary set $Y$ satisfying contractive condition (7). Assume that $T(Y) \subseteq S(Y)$, $S(Y)$ is a complete subspace of $X$ and $S z=T z=p$ (say). For $x_{0} \in Y$, let Jungck-Mann iterative scheme be defined by (JM) and Jungck-Ishikawa iterative scheme be defined by (JI), with $\alpha_{n} \in[0,1 /(1+(1+2 / m) a)], \beta_{n} \leq 1-\alpha_{n}(1-a)$, for some $m>0$ and $n \in N$ satisfying $\sum_{n=0}^{\infty} \alpha_{n}=\infty$.

Then, the Jungck-Ishikawa iterative scheme converges faster than Jungck-Mann iterative scheme to $p$.

Proof. For Jungck-Mann iterative scheme, we have

$$
\begin{aligned}
\left\|S x_{n+1}-p\right\| & \geq\left(1-\alpha_{n}\right)\left\|S x_{n}-p\right\|-\alpha_{n}\left\|T x_{n}-p\right\| \\
& \geq\left(1-\alpha_{n}\right)\left\|S x_{n}-p\right\|-\alpha_{n} a\left\|S x_{n}-p\right\| \\
& \geq\left[1-\alpha_{n}(1+a)\right]\left\|S u_{n}-p\right\| .
\end{aligned}
$$

Also, for Jungck-Ishikawa iterative scheme, we have

$$
\begin{aligned}
\left\|S x_{n+1}-p\right\| & \leq\left(1-\alpha_{n}\right)\left\|S x_{n}-p\right\|+a\left\|T y_{n}-p\right\| \\
& \leq\left(1-\alpha_{n}\right)\left\|S x_{n}-p\right\|+\alpha_{n} a\left\|S y_{n}-p\right\| .
\end{aligned}
$$

But

$$
\begin{aligned}
\left\|S x_{n+1}-p\right\| & \leq\left(1-\beta_{n}\right)\left\|S x_{n}-p\right\|+\beta_{n}\left\|T x_{n}-p\right\| \\
& \leq\left(1-\beta_{n}(1-a)\right)\left\|S x_{n}-p\right\| .
\end{aligned}
$$

Hence,

$$
\left\|S x_{n+1}-p\right\| \leq\left(1-\alpha_{n}(1-a)-\alpha_{n} \beta_{n} a(1-a)\right)\left\|T x_{n}-p\right\| .
$$

Using (24) and (27), we have

$$
\left\|\frac{\mathrm{JI}_{n+1}}{\mathrm{JM}_{n+1}}\right\| \leq \prod_{i=0}^{n}\left[\frac{\left(1-\alpha_{i}(1-a)-\alpha_{i} \beta_{i} a(1-a)\right)}{\left(1-\alpha_{i}(1+a)\right)}\right] .
$$

But we observe that

$$
\frac{1-\alpha_{i}(1-a)}{1-\alpha_{i}(1+a)} \leq 1+m \quad \forall i=0,1,2, \ldots .
$$

Using (29) together with $\beta_{n} \leq 1-\alpha_{n}(1-a)$, we have

$$
\begin{aligned}
& \prod_{i=0}^{n}\left[\frac{\left(1-\alpha_{i}(1-a)-\alpha_{i} \beta_{i} a(1-a)\right)}{\left(1-\alpha_{i}(1+a)\right)}\right] \\
& \quad \leq(1+m)\left(1-\alpha_{i}(1-a)\right) \leq(1+m) e^{-\alpha_{i}(1-a)} .
\end{aligned}
$$

As $\sum_{n=0}^{\infty} \alpha_{n}=\infty$, so (28) yields $\lim _{n \rightarrow \infty} \|\left(\mathrm{JI}_{n+1}-p\right) /\left(\mathrm{JM}_{n+1}-\right.$ p) $\|=0$.

Therefore, by Definition 4, Jungck-Ishikawa iterative scheme converges faster than Jungck-Mann iterative scheme to $p$.

Theorem 15. Let $(X,\|\cdot\|)$ be an arbitrary Banach space, and let $S, T: Y \rightarrow X$ be nonself-operators on an arbitrary set $Y$ satisfying contractive condition (7). Assume that $T(Y) \subseteq S(Y)$,
$S(Y)$ is a complete subspace of $X$, and $S z=T z=p$ (say). For $x_{0} \in Y$, let Jungck-Noor iterative scheme be defined by (JN) and Jungck-Ishikawa iterative scheme defined by (JI), with $\alpha_{n} \in$ $[0,1 /(1+(1+2 / m) a)], \beta_{n} \leq 1-\alpha_{n}(1-a)$, for some $m>0$ and $n \in N$ satisfying $\sum_{n=0}^{\infty} \alpha_{n}=\infty$. Then, the Jungck-Noor iterative scheme converges faster than Jungck-Ishikawa iterative scheme to $p$.

Proof. For Jungck-Ishikawa iterative scheme, we have

$$
\left\|S x_{n+1}-p\right\| \geq\left[1-\alpha_{n}(1+a)\right]\left\|S u_{n}-p\right\| .
$$

Also, for Jungck-Noor iterative scheme, we have

$$
\begin{aligned}
& \left\|S x_{n+1}-p\right\| \\
& \leq\left(1-\alpha_{n}(1-a)-\alpha_{n} \beta_{n} a(1-a)-\alpha_{n} \beta_{n} \gamma_{n} a^{2}(1-a)\right) \\
& \quad \times\left\|T x_{n}-p\right\| .
\end{aligned}
$$

Using (31) and (32), we have

$$
\begin{aligned}
& \left\|\frac{\mathrm{JN}_{n+1}}{\mathrm{JI}_{n+1}}\right\| \\
& \leq \prod_{i=0}^{n}\left[\frac{\left(1-\alpha_{i}(1-a)-\alpha_{i} \beta_{i} a(1-a)-\alpha_{n} \beta_{n} \gamma_{n} a^{2}(1-a)\right)}{\left(1-\alpha_{i}(1+a)\right)}\right] . \\
& \leq \prod_{i=0}^{n}\left[\frac{1-\alpha_{i}(1-a)-\alpha_{i} \beta_{i} a(1-a)}{\left(1-\alpha_{i}(1+a)\right)}\right]
\end{aligned}
$$

Making the same calculations as in Theorem 14, (33) yields

$$
\lim _{n \rightarrow \infty}\left\|\frac{\mathrm{JN}_{n+1}-p}{\mathrm{JI}_{n+1}-p}\right\|=0 .
$$

By Definition 4, Jungck-Noor iterative scheme converges faster than Jungck-Ishikawa iterative scheme to $p$.

Theorem 16. Let $(X,\|\cdot\|)$ be an arbitrary Banach space and $S, T: Y \rightarrow X$ be nonself operators on an arbitrary set $Y$ satisfying contractive condition (7). Assume that $T(Y) \subseteq S(Y)$, $S(Y)$ is a complete subspace of $X$ and $S z=T z=p$ (say). For $x_{0} \in Y$, let Jungck-Noor iterative scheme be defined by (JN) and Jungck-SP iterative scheme defined by (JSP), with $\alpha_{n} \in[0,1 /(1+(1+2 / m) a)]$, for some $m>0$ satisfying $\sum_{n=0}^{\infty} \beta_{n}=\infty$. Then, the Jungck-SP iterative scheme converges faster than Jungck-Noor iterative scheme to $p$.

Proof. For Jungck-Noor iterative scheme, we have

$$
\left\|S x_{n+1}-p\right\| \geq\left[1-\alpha_{n}(1+a)\right]\left\|S u_{n}-p\right\| .
$$

Also, for Jungck-SP iterative scheme, we have

$$
\begin{aligned}
& \left\|S x_{n+1}-p\right\| \\
& \leq\left(1-\alpha_{n}(1-a)\right)\left(1-\beta_{n}(1-a)\right) \\
& \quad \times\left(1-\gamma_{n}(1-a)\right)\left\|T x_{n}-p\right\| .
\end{aligned}
$$


Using (35) and (36), we have

$$
\begin{aligned}
& \left\|\frac{\mathrm{JSP}_{n+1}-p}{\mathrm{JN}_{n+1}-p}\right\| \\
& \quad \leq \prod_{i=0}^{n}\left[\frac{\left(1-\alpha_{n}(1-a)\right)\left(1-\beta_{n}(1-a)\right)\left(1-\gamma_{n}(1-a)\right)}{\left(1-\alpha_{i}(1+a)\right)}\right] \\
& \quad \leq \prod_{i=0}^{n}\left[\frac{\left(1-\alpha_{n}(1-a)\right)\left(1-\beta_{n}(1-a)\right)}{\left(1-\alpha_{i}(1+a)\right)}\right] .
\end{aligned}
$$

We observe that

$$
\frac{1-\alpha_{i}(1-a)}{1-\alpha_{i}(1+a)} \leq 1+m \quad \forall i=0,1,2, \ldots .
$$

Using (38) together with $\sum_{n=0}^{\infty} \beta_{n}=\infty$, (37) yields

$$
\lim _{n \rightarrow \infty}\left\|\frac{\mathrm{JSP}_{n+1}-p}{\mathrm{JN}_{n+1}-p}\right\|=0 .
$$

Therefore, by Definition 4, Jungck-SP iterative scheme converges faster than Jungck-Noor iterative scheme $p$.

Theorem 17. Let $(X,\|\cdot\|)$ be an arbitrary Banach space, and let $S, T: Y \rightarrow X$ be nonself operators on an arbitrary set $Y$ satisfying contractive condition (7). Assume that $T(Y) \subseteq$ $S(Y), S(Y)$ is a complete subspace of $X$ and $S z=T z=p$ (say). For $x_{0} \in Y$, let Jungck-Agarwal's et al. iterative scheme be defined by (JA) and Jungck-SP iterative scheme be defined by (JSP) with (i) $\sum_{n=0}^{\infty} \alpha_{n}=\infty$, (ii) $\lim _{n \rightarrow \infty} \alpha_{n}=0$, and (iii) $\lim _{n \rightarrow \infty} \beta_{n}=0$. Then, the Jungck-Agarwal iterative scheme converges faster than Jungck-SP iterative scheme to $p$.

Proof. For Jungck-SP iterative scheme, we have

$$
\left\|S x_{n+1}-p\right\| \geq\left[1-\alpha_{n}(1+a)\right]\left\|S x_{n}-p\right\| .
$$

Also, for Jungck-Agarwal iterative scheme, we have

$$
\left\|S x_{n+1}-p\right\| \leq a\left(1-\alpha_{n} \beta_{n}(1-a)\right)\left\|T x_{n}-p\right\| .
$$

Using (40) and (41), we have

$$
\left\|\frac{\mathrm{JSP}_{n+1}-p}{\mathrm{JA}_{n+1}-p}\right\| \leq a^{n} \prod_{i=0}^{n}\left[\frac{\left(1-\alpha_{n} \beta_{n}(1-a)\right)}{\left(1-\alpha_{i}(1+a)\right)}\right] .
$$

Since $a \in[0,1)$ and $\lim _{n \rightarrow \infty} \alpha_{n}=0, \lim _{n \rightarrow \infty} \beta_{n}=0$.

Hence from (42), we have

$$
\lim _{n \rightarrow \infty}\left\|\frac{\mathrm{JSP}_{n+1}-p}{\mathrm{JA}_{n+1}-p}\right\|=0 .
$$

Therefore, by Definition 4, Jungck-SP iterative scheme converges faster than Jungck-Agarwal et al.s iterative scheme to $p$.

Theorem 18. Let $(X,\|\cdot\|)$ be an arbitrary Banach space, and let $S, T: Y \rightarrow X$ be nonself-operators on an arbitrary set $Y$ satisfying contractive condition (7). Assume that $T(Y) \subseteq S(Y)$,
$S(Y)$ is a complete subspace of $X$ and $S z=T z=p$ (say). For $x_{0} \in Y$, let Jungck-S iterative scheme be defined by (JS) and Jungck-Agarwal iterative scheme defined by (JA). Then, the Jungck-S iterative scheme converges faster than JungckAgarwal iterative scheme to $p$.

Proof. For Jungck-S iterative scheme, we have

$$
\left\|S x_{n+1}-p\right\| \leq a\left(1-\alpha_{n}(1-a)\right)\left\|S x_{n}-p\right\| .
$$

Also, for Jungck-Agarwal iterative scheme, we have

$$
\left\|S x_{n+1}-p\right\| \leq a\left(1-\alpha_{n} \beta_{n}(1-a)\right)\left\|S x_{n}-p\right\| .
$$

It is obvious that

$$
a\left(1-\alpha_{n}(1-a)\right) \leq a\left(1-\alpha_{n} \beta_{n}(1-a)\right) \quad \forall n
$$

Hence by Definition 3, Jungck-S iterative scheme converges faster than Jungck-Agarwal iterative scheme.

Theorem 19. Let $(X,\|\cdot\|)$ be an arbitrary Banach space, and let $S, T: Y \rightarrow X$ be nonself operators on an arbitrary set $Y$ satisfying contractive condition (7). Assume that $T(Y) \subseteq S(Y)$, $S(Y)$ is a complete subspace of $X$ and $S z=T z=p$ (say). For $x_{0} \in Y$, let Jungck-S iterative scheme be defined by (JS) and Jungck-CR iterative scheme be defined by (JCR). Then, the Jungck-CR iterative scheme converges faster than Jungck-S iterative scheme to $p$.

Proof. For Jungck-S iterative scheme, we have

$$
\left\|S x_{n+1}-p\right\| \leq a\left(1-\alpha_{n}(1-a)\right)\left\|S x_{n}-p\right\| .
$$

Also, for Jungck-CR iterative scheme, we have

$$
\begin{aligned}
& \left\|S x_{n+1}-p\right\| \\
& \quad \leq a\left(1-\alpha_{n}(1-a)\right)\left(1-\beta_{n} \gamma_{n}(1-a)\right)\left\|S x_{n}-p\right\| .
\end{aligned}
$$

It is obvious that

$$
\begin{aligned}
& a\left(1-\alpha_{n}(1-a)\right)\left(1-\beta_{n} \gamma_{n}(1-a)\right) \\
& \quad \leq a\left(1-\alpha_{n}(1-a)\right) \quad \forall n .
\end{aligned}
$$

Hence by Definition 3, Jungck-CR iterative scheme converges faster than Jungck-S iterative scheme.

The following example supports the above results.

Example 20. Let $Y=[0,1], X=[0,1 / 2], S: Y \rightarrow X=x / 2$, $T: Y \rightarrow X=x / 4, \alpha_{n}=\beta_{n}=\gamma_{n}=0, n=1,2 \ldots n_{0}-1$ for some $n_{0} \in N$, and $\alpha_{n}=\beta_{n}=\gamma_{n}=4 / \sqrt{n}, n \geq n_{0}$. It is clear that $T$ and $S$ are quasicontractive operators satisfying (7) with the unique common fixed point 0 . Also, it is easy to see that Example 20 satisfies all the conditions of Theorem 8 and Theorems 14-19. 
Proof. For JM, JI, JN, JA, JS, JSP, and JCR iterative schemes with initial approximation $x_{0} \neq 0$, we have

$$
\begin{gathered}
\mathrm{JM}_{n}=\prod_{i=n_{0}}^{n}\left(\frac{1}{2}-\frac{1}{\sqrt{i}}\right) x_{0}, \\
\mathrm{JI}_{n}=\prod_{i=n_{0}}^{n}\left(\frac{1}{2}-\frac{1}{\sqrt{i}}-\frac{2}{i}\right) x_{0}, \\
\mathrm{JN}_{n}=\prod_{i=n_{0}}^{n}\left(1-\frac{2}{\sqrt{i}}-\frac{4}{i}-\frac{8}{i^{3 / 2}}\right) x_{0}, \\
\mathrm{JSP}_{n}=\prod_{i=n_{0}}^{n}\left(\frac{1}{2}-\frac{3}{\sqrt{i}}+\frac{6}{i}-\frac{4}{i^{3 / 2}}\right) x_{0}, \\
\mathrm{JA}_{n}=\prod_{i=n_{0}}^{n}\left(\frac{1}{4}-\frac{2}{i}\right) x_{0}, \\
\mathrm{JS}_{n}=\prod_{i=n_{0}}^{n}\left(\frac{1}{4}-\frac{2}{i}\right) x_{0}, \\
\mathrm{JCR}_{n}=\prod_{i=n_{0}}^{n}\left(\frac{1}{4}-\frac{1}{2 \sqrt{i}}-\frac{2}{i}+\frac{4}{i^{3 / 2}}\right) x_{0} .
\end{gathered}
$$

Now, for $n_{0}=16$, consider

$$
\begin{aligned}
\left|\frac{\mathrm{JI}_{n+1}}{\mathrm{JM}_{n+1}}\right| & =\left|\frac{\prod_{i=16}^{n}(1-2 / \sqrt{i}-4 / i) x_{0}}{\prod_{i=16}^{n}(1-2 / \sqrt{i}) x_{0}}\right| \\
& =\left|\prod_{i=16}^{n}\left[1-\frac{4 / i}{(1-2 / \sqrt{i})}\right]\right| \\
& =\left|\prod_{i=16}^{n}\left[1-\frac{4}{(i-2 \sqrt{i})}\right]\right|
\end{aligned}
$$

It is easy to see that

$$
\begin{aligned}
0 & \leq \lim _{n \rightarrow \infty} \prod_{i=16}^{n}\left[1-\frac{4}{(i-2 \sqrt{i})}\right] \\
& \leq \lim _{n \rightarrow \infty} \prod_{i=16}^{n}\left(1-\frac{1}{i}\right)=\lim _{n \rightarrow \infty} \frac{15}{n}=0 .
\end{aligned}
$$

Hence, $\lim _{n \rightarrow \infty}\left|\mathrm{JI}_{n+1} / \mathrm{JM}_{n+1}\right|=0$.

Therefore, by Definition 4, Jungck-Ishikawa iterative scheme converges faster than Jungck-Mann iterative scheme to the common fixed point 0 of $T$ and $S$.

Similarly, for $n_{0}=16$,

$$
\begin{aligned}
\left|\frac{\mathrm{JN}_{n}}{\mathrm{JI}_{n}}\right| & =\left|\frac{\prod_{i=16}^{n}\left(1-2 / \sqrt{i}-4 / i-8 / i^{3 / 2}\right) x_{0}}{\prod_{i=16}^{n}(1-2 / \sqrt{i}-4 / i) x_{0}}\right| \\
& =\left|\prod_{i=16}^{n}\left[1-\frac{8 / i^{3 / 2}}{1-2 / \sqrt{i}-4 / i}\right]\right| \\
& =\left|\prod_{i=16}^{n}\left[1-\frac{8}{\left(i^{3 / 2}-2 i-4 \sqrt{i}\right)}\right]\right|
\end{aligned}
$$

with

$$
\begin{aligned}
0 & \leq \lim _{n \rightarrow \infty} \prod_{i=16}^{n}\left[1-\frac{8}{\left(i^{3 / 2}-2 i-4 \sqrt{i}\right)}\right] \\
& \leq \lim _{n \rightarrow \infty} \prod_{i=16}^{n}\left(1-\frac{1}{i}\right)=\lim _{n \rightarrow \infty} \frac{15}{n}=0
\end{aligned}
$$

implies

$$
\lim _{n \rightarrow \infty}\left|\frac{\mathrm{JN}_{n}}{\mathrm{JI}_{n}}\right|=0
$$

Therefore, by Definition 4, JN iterative scheme converges faster than JI iterative scheme to the common fixed point 0 of $T$ and $S$.

Again, similarly, for $n_{0}=100$,

$$
\begin{aligned}
\left|\frac{\mathrm{JSP}_{n}}{\mathrm{JN}_{n}}\right| & =\left|\frac{\prod_{i=100}^{n}\left(1-6 / \sqrt{i}+12 / i-8 / i^{3 / 2}\right) x_{0}}{\prod_{i=100}^{n}\left(1-2 / \sqrt{i}-4 / i-8 / i^{3 / 2}\right) x_{0}}\right| \\
& =\left|\prod_{i=100}^{n}\left[1-\frac{(4 / \sqrt{i}-16 / i)}{1-2 / \sqrt{i}-4 / i-8 / i^{3 / 2}}\right]\right| \\
& =\left|\prod_{i=100}^{n}\left[1-\frac{(4 i-16 \sqrt{i})}{\left(i^{3 / 2}-2 i-4 \sqrt{i}-8\right)}\right]\right|
\end{aligned}
$$

with

$$
\begin{aligned}
0 & \leq \lim _{n \rightarrow \infty} \prod_{i=100}^{n}\left[1-\frac{(4 i-16 \sqrt{i})}{\left(i^{3 / 2}-2 i-4 \sqrt{i}-8\right)}\right] \\
& \leq \lim _{n \rightarrow \infty} \prod_{i=100}^{n}\left(1-\frac{1}{i}\right)=\lim _{n \rightarrow \infty} \frac{99}{n}=0
\end{aligned}
$$

implies

$$
\lim _{n \rightarrow \infty}\left|\frac{\mathrm{JSP}_{n}}{\mathrm{JN}_{n}}\right|=0
$$

Therefore, by Definition 4, JSP iterative scheme converges faster than JN iterative scheme to the common fixed point 0 of $T$ and $S$.

Again, similarly, for $n_{0}=100$,

$$
\begin{aligned}
\left|\frac{\mathrm{JA}_{n}}{\mathrm{JSP}_{n}}\right| & =\left|\frac{\prod_{i=100}^{n}(1 / 2-4 / i) x_{0}}{\prod_{i=100}^{n}\left(1-6 / \sqrt{i}+12 / i-8 / i^{3 / 2}\right) x_{0}}\right| \\
& =\left|\prod_{i=100}^{n}\left[1-\frac{\left(1 / 2-6 / \sqrt{i}+16 / i-8 / i^{3 / 2}\right)}{1-6 / \sqrt{i}+12 / i-8 / i^{3 / 2}}\right]\right| \\
& =\left|\prod_{i=100}^{n}\left[1-\frac{\left(i^{3 / 2}-12 i+32 \sqrt{i}-16\right)}{\left(2 i^{3 / 2}-12 i+24 \sqrt{i}-16\right)}\right]\right|
\end{aligned}
$$

with

$$
\begin{aligned}
0 & \leq \lim _{n \rightarrow \infty} \prod_{i=100}^{n}\left[1-\frac{\left(i^{3 / 2}-12 i+32 \sqrt{i}-16\right)}{\left(2 i^{3 / 2}-12 i+24 \sqrt{i}-16\right)}\right] \\
& \leq \lim _{n \rightarrow \infty} \prod_{i=100}^{n}\left(1-\frac{1}{i}\right)=\lim _{n \rightarrow \infty} \frac{99}{n}=0
\end{aligned}
$$


implies

$$
\lim _{n \rightarrow \infty}\left|\frac{\mathrm{JA}_{n}}{\mathrm{JSP}_{n}}\right|=0 .
$$

Therefore, by Definition 4, JA iterative scheme converges faster than JSP iterative scheme to the common fixed point 0 of $T$ and $S$.

$$
\begin{aligned}
& \text { Again, for } n_{0}=16 \\
& \qquad \begin{aligned}
\left|\frac{\mathrm{JS}_{n}}{\mathrm{JA}_{n}}\right| & =\left|\frac{\prod_{i=16}^{n}(1 / 2-1 / \sqrt{i}) x_{0}}{\prod_{i=16}^{n}(1 / 2-4 / i) x_{0}}\right| \\
& =\left|\prod_{i=16}^{n}\left[1-\frac{(1 / \sqrt{i}-4 / i)}{1 / 2-4 / i}\right]\right| \\
& =\left|\prod_{i=16}^{n}\left[1-\frac{(2 \sqrt{i}-8)}{i-8}\right]\right|
\end{aligned}
\end{aligned}
$$

with

$$
\begin{aligned}
0 & \leq \lim _{n \rightarrow \infty} \prod_{i=16}^{n}\left[1-\frac{(2 \sqrt{i}-8)}{i-8}\right] \\
& \leq \lim _{n \rightarrow \infty} \prod_{i=16}^{n}\left(1-\frac{1}{i}\right)=\lim _{n \rightarrow \infty} \frac{15}{n}=0
\end{aligned}
$$

implies

$$
\lim _{n \rightarrow \infty}\left|\frac{\mathrm{JS}_{n}}{\mathrm{JA}_{n}}\right|=0 .
$$

Therefore, by Definition 4, JS iterative scheme converges faster than JA iterative scheme to the common fixed point 0 of $T$ and $S$.

Similarly, again, for $n_{0}=16$,

$$
\begin{aligned}
\left|\frac{\mathrm{JCR}_{n}}{\mathrm{JS}_{n}}\right| & =\left|\frac{\prod_{i=16}^{n}\left(1 / 2-1 / \sqrt{i}-4 / i+8 / i^{3 / 2}\right) x_{0}}{\prod_{i=16}^{n}(1 / 2-1 / \sqrt{i}) x_{0}}\right| \\
& =\left|\prod_{i=16}^{n}\left[1-\frac{\left(4 / i-8 / i^{3 / 2}\right)}{1 / 2-1 / \sqrt{i}}\right]\right| \\
& =\left|\prod_{i=16}^{n}\left[1-\frac{(8 \sqrt{i}-16)}{i^{3 / 2}-2 i}\right]\right|
\end{aligned}
$$

with

$$
\begin{aligned}
0 & \leq \lim _{n \rightarrow \infty} \prod_{i=16}^{n}\left[1-\frac{(8 \sqrt{i}-16)}{i^{3 / 2}-2 i}\right] \\
& \leq \lim _{n \rightarrow \infty} \prod_{i=16}^{n}\left(1-\frac{1}{i}\right)=\lim _{n \rightarrow \infty} \frac{15}{n}=0
\end{aligned}
$$

implies

$$
\lim _{n \rightarrow \infty}\left|\frac{\mathrm{JCR}_{n}}{\mathrm{JS}_{n}}\right|=0
$$

Therefore, by Definition 4, JCR iterative scheme converges faster than JS iterative scheme to the common fixed point 0 of $T$ and $S$.

From Example 20, we observe that the decreasing order of Jungck-type iterative schemes is as follows:

JCR, JS, JA, JSP, JN, JI, and JM.

\section{Applications}

4.1. Jungck-Type Iterative Schemes in RNN Analysis. Recurrent neural networks (RNNs) are a class of densely connected single-layer nonlinear networks of perceptrons. RNNs not only operate on an input space but also on an internal statespace. This is equivalent to a with-memory Iterated Function System [28]. The state space enables the representation (and learning) of temporally/sequentially extended dependencies over unspecified (and potentially infinite) intervals according to

$$
\begin{gathered}
y(t)=G(s(t)) \\
s(t)=F(s(t-1), x(t)) .
\end{gathered}
$$

Because of the network's nonlinearity, a number of undesirable local energy minima emerge from the learning procedure. This has been shown to significantly affect the network's performance. The iterative schemes like Mann, Ishikawa and $J$-iteration may be used to estimate the number of iterations required to achieve a stable state in recurrent autoassociative neural networks.

4.1.1. Decreasing Function $(1-x)^{9}$. In order to solve this function by Jungck-type iterative schemes, we write it in the form $S x=T x$, where the functions $T, S:[0,1] \rightarrow[0,2]$ are defined as $T(x)=(1-x)^{9}$ and $S x=x$, respectively. By taking initial approximation $x_{0}=0.8$ and $\alpha_{n}=\beta_{n}=$ $\gamma_{n}=1 / \sqrt[4]{n+1}$, the obtained results are listed in Table 3 showing convergence of different Jungck-type schemes to $p=$ $0.175699=T 0.175699=S 0.175699$.

4.1.2. Increasing Function $x^{2}-2 x-3$. In order to solve this function by Jungck-type iterative schemes, we write it in the form $S x=T x$, where the functions $T, S:[3,4] \rightarrow[9,16]$ are defined as $T x=2 x+3$ and $S x=x^{2}$, respectively. By taking initial approximation $x_{0}=4$ and $\alpha_{n}=\beta_{n}=\gamma_{n}=1 / \sqrt[4]{n+1}$, the obtained results are listed in Table 4 showing convergence of different Jungck-type schemes to $p=9=T 3=S 3$.

4.1.3. Oscillating Function $1 / x$. In order to solve this function by Jungck-type iterative schemes, we write it in the form $S x=T x$, where the functions $T, S:[0.5,2] \rightarrow[0.25,4]$ are defined as $T x=1 / x$ and $S x=x^{2}$, respectively. By taking initial approximation $x_{0}=2$ and $\alpha_{n}=\beta_{n}=\gamma_{n}=1 / \sqrt[4]{n+1}$, the obtained results are listed in Table 5 showing convergence of different Jungck type schemes to $p=1=T 1=S 1$.

4.1.4. Biquadratic Equation $x^{4}-36 x^{2}-52 x+87=0$. In order to solve this equation, we rewrite it in the form $S x=T x$, 


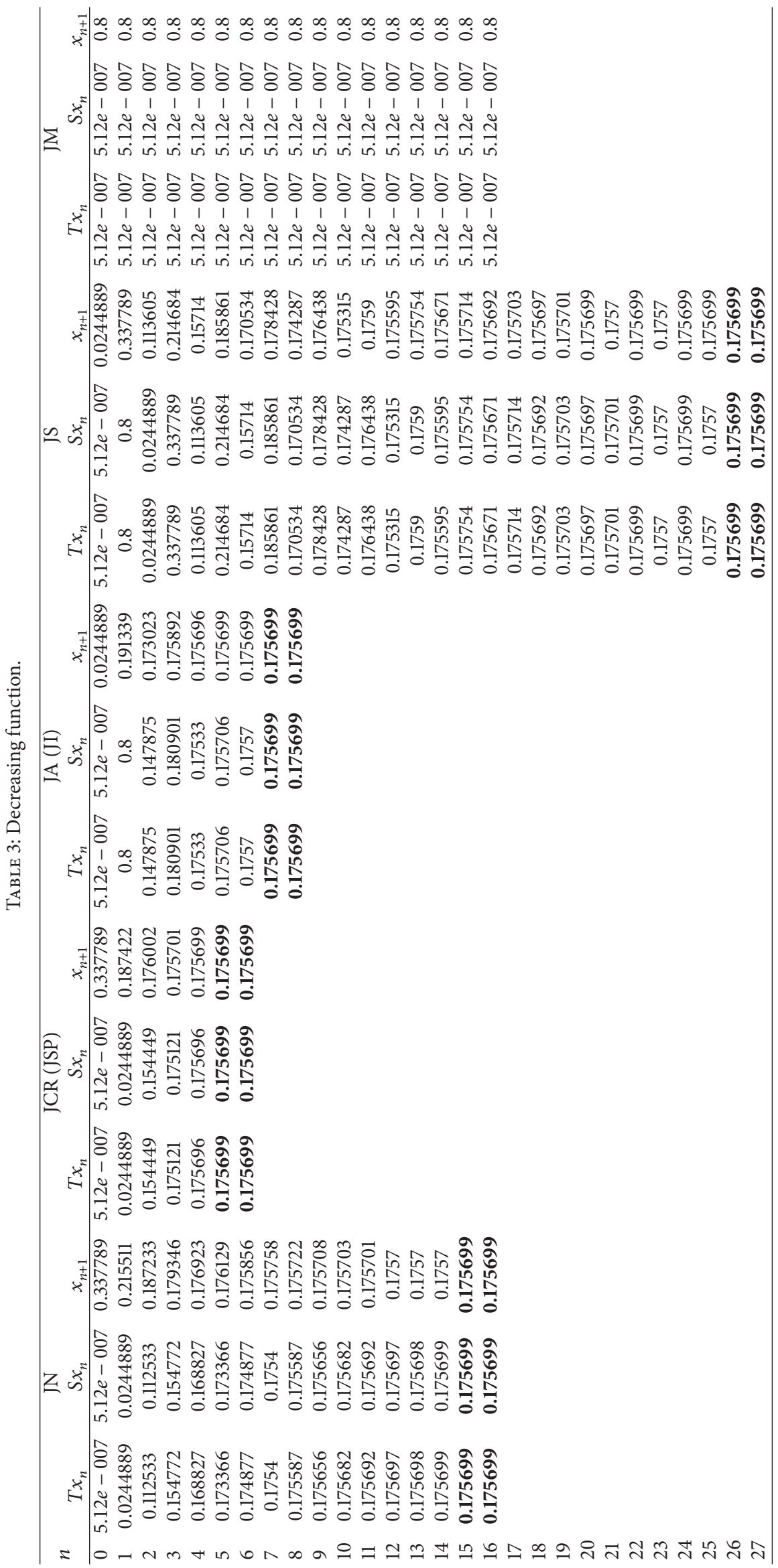




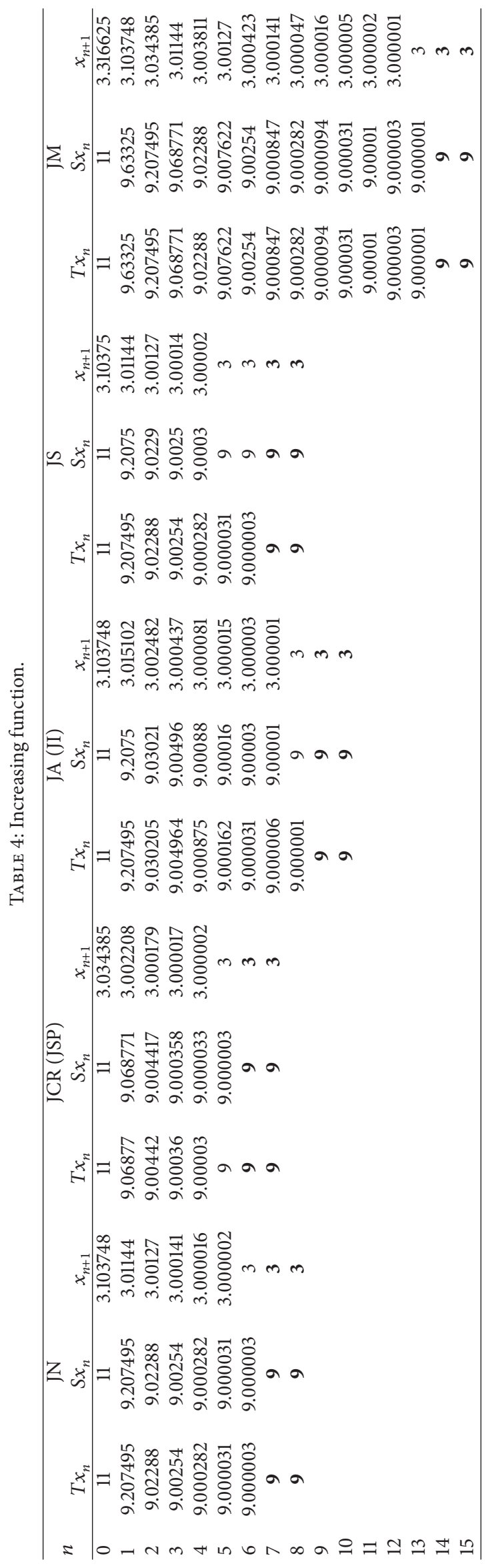




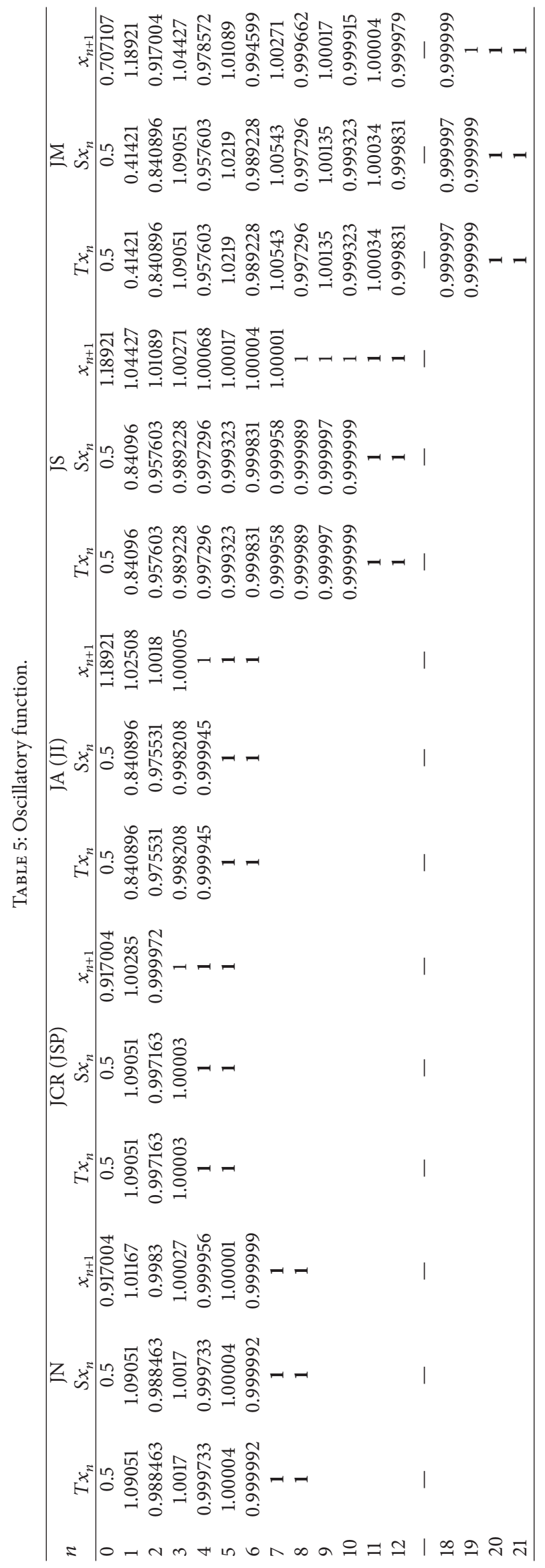


where the functions $T, S:[0.5,1.5] \rightarrow[9,81]$ are defined as $T x=x^{4}-52 x+87$ and $S x=36 x^{2}$, respectively. Taking initial approximation $x_{0}=0.5$ and $\alpha_{n}=\beta_{n}=\gamma_{n}=1 / \sqrt[2]{n+1}$, the obtained results are listed in Table 6 showing convergence of different Jungck-type schemes to $p=36=T 1=S 1$.

For detailed study, these programs are again executed after changing the parameters, and some observations are given as below.

\section{Decreasing Function}

(1) Taking initial guess $x_{o}=0.3$ (near common fixed point), Jungck-Noor iterative scheme converges in 14 iterations, Jungck-Ishikawa and Jungck-Agarwal iterative schemes converge in a similar manner in 8 iterations, Jungck-CR and the Jungck-SP iterative schemes converge in a similar manner in 5 iterations, and Jungck-S iterative scheme converges in 25 iterations while Jungck-Mann iterative scheme shows strange constant behavior.

(2) Taking $\alpha_{n}=\beta_{n}=\gamma_{n}=1 /(1+n)^{1 / 6}$ and $x_{o}=0.8$, we observe that Jungck-Noor iterative scheme converges in 13 iterations, Jungck-Ishikawa and Jungck-Agarwal iterative schemes converge in a similar manner in 11 iterations, Jungck-CR and the Jungck-SP iterative schemes converge in a similar manner in 8 iterations, and Jungck-S iterative scheme converges in 27 iterations while Jungck-Mann iterative scheme shows strange constant behavior.

\section{Increasing Functions}

(1) Taking initial guess $x_{o}=3.2$ (near coincidence point), Jungck-Noor iterative scheme converges in 7 iterations, Jungck-Ishikawa and Jungck-Agarwal iterative schemes converge in a similar manner in 8 iterations, Jungck-CR and the Jungck-SP iterative schemes converge in a similar manner in 6 iterations, and Jungck-S iterative scheme converges in 7 iterations while Jungck-Mann iterative scheme converges in 13 iterations.

(2) Taking $\alpha_{n}=\beta_{n}=\gamma_{n}=1 /(1+n)^{1 / 6}$ and $x_{o}=4$, we observe that Jungck-Noor iterative scheme converges in 7 iterations, Jungck-Ishikawa and Jungck-Agarwal iterative schemes converge in a similar manner in 8 iterations, Jungck-CR and the Jungck-SP iterative schemes converge in a similar manner in 6 iterations, and Jungck-S iterative scheme converges in 7 iterations while Jungck-Mann iterative scheme converges in 14 iterations.

\section{Oscillatory Function}

(1) Taking initial guess $x_{o}=1.3$ (near common fixed point), Jungck-Noor iterative scheme converges in 8 iterations, Jungck-Ishikawa and Jungck-Agarwal iterative schemes converge in a similar manner in 6 terations, Jungck-CR and the Jungck-SP iterative schemes converge in a similar manner in 5 iterations, Jungck-S iterative scheme converges in 11 iterations while Jungck-Mann iterative scheme converges in 19 iterations.

(2) Taking $\alpha_{n}=\beta_{n}=\gamma_{n}=1 /(1+n)^{1 / 6}$ and $x_{o}=2$, we observe that Jungck-Noor iterative scheme converges in 8 iterations, Jungck-Ishikawa and Jungck-Agarwal iterative schemes converge in a similar manner in 9 iterations, Jungck-CR and the Jungck-SP iterative schemes converge in a similar manner in 6 iterations, Jungck-S iterative scheme converges in 12 iterations while Jungck-Mann iterative scheme converges in 21 iterations.

\section{Biquadratic Equation}

(1) Taking initial guess $x_{o}=0.8$ (near coincidence point), Jungck-Noor iterative scheme converges in 11 iterations, Jungck-Ishikawa and Jungck-Agarwal iterative schemes converge in a similar manner in 7 iterations, Jungck-CR and the Jungck-SP iterative schemes converge in a similar manner in 4 iterations, and Jungck$\mathrm{S}$ iterative scheme converges in 18 iterations while Jungck-Mann iterative scheme converges in 35 iterations.

(2) Taking $\alpha_{n}=\beta_{n}=\gamma_{n}=1 /(1+n)^{1 / 4}$ and $x_{o}=0.5$, we observe that Jungck-Noor iterative scheme converges in 12 iterations, Jungck-Ishikawa and Jungck-Agarwal iterative schemes converge in a similar manner in 8 iterations, Jungck-CR and the Jungck-SP iterative schemes converge in a similar manner in 6 iterations, and Jungck-S iterative scheme converges in 19 iterations while Jungck-Mann iterative scheme converges in 37 iterations.

\section{Conclusions}

The speed of iterative schemes depends on $\alpha_{n}, \beta_{n}$, and $\gamma_{n}$. From Tables 3-6 and observations made above, we make the following conjectures.

\subsection{Decreasing Function}

(1) Decreasing order of rate of convergence of Jungck type iterative schemes is as follows: Jungck-CR (Jungck-SP), Jungck-Agarwal (Jungck-Ishikawa), Jungck-Noor, and Jungck-S iterative scheme.

(2) For initial guess near to common fixed point, JungckCR (Jungck-SP), Jungck-Noor, and Jungck-S iterative schemes show a decrease while Jungck-Agarwal (Jungck-Ishikawa) iterative scheme shows no change in the number of iterations to converge.

\subsection{Increasing Functions}

(1) Decreasing order of rate of convergence of Jungcktype iterative schemes is as follows: Jungck-CR 


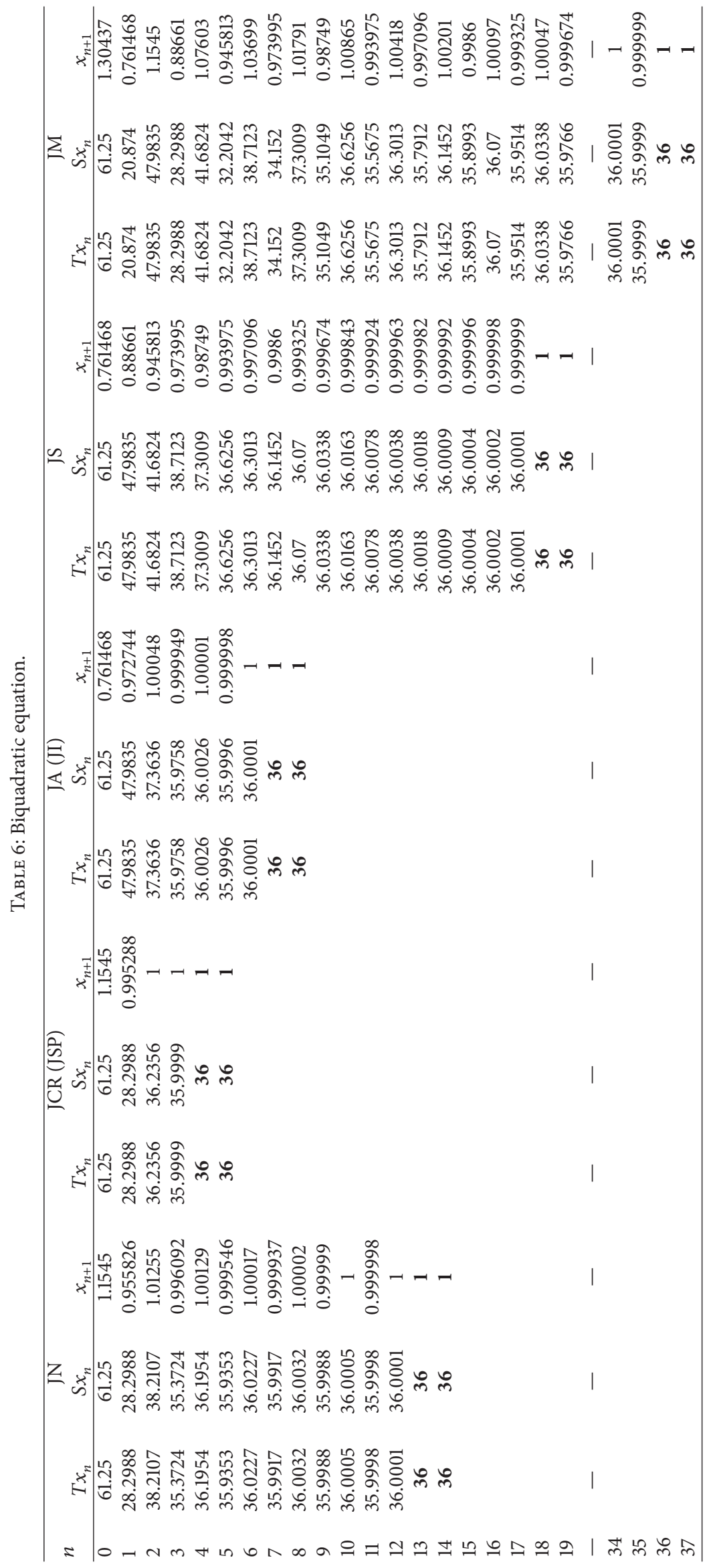


(Jungck-SP), Jungck-S (Jungck-Noor), Jungck-Agarwal (Jungck-Ishikawa), and Jungck Mann iterative scheme.

(2) For initial guess near to the coincidence point, all Jungck-type iterative schemes show a decrease in the number of iterations to converge.

\subsection{Oscillatory Functions}

(1) Decreasing order of rate of convergence of Jungcktype iterative schemes is as follows: Jungck-CR (Jungck-SP), Jungck-Agarwal (Jungck-Ishikawa), Jungck-Noor, Jungck-S, and Jungck-Mann iterative scheme.

(2) For initial guess near to the common fixed point, Jungck-Mann and Jungck-S iterative schemes show a decrease while Jungck-CR (Jungck-SP), JungckAgarwal (Jungck-Ishikawa), and Jungck-Noor iterative schemes show no change in the number of iterations to converge.

\subsection{Biquadratic Equation}

(1) Decreasing order of rate of convergence of Jungck type iterative schemes is as follows: Jungck-CR (Jungck-SP), Jungck-Agarwal (Jungck-Ishikawa), Jungck-Noor, Jungck-S, and Jungck-Mann iterative scheme.

(2) For initial guess near to the coincidence point, all Jungck-type iterative schemes show a decrease in the number of iterations to converge.

Remark 21. In each case mentioned above, Jungck-CR and Jungck-SP iterative schemes have better convergence rate as compared to other iterative schemes and hence have a good potential for further applications.

\section{Acknowledgments}

This research was funded by the Deanship of Scientific Research (DSR), King Abdulaziz University, Jeddah, Saudi Arabia. The first and third authors acknowledge with thanks DSR, KAU, Saudi Arabia, for financial support.

\section{References}

[1] G. Jungck, "Commuting mappings and fixed points," The American Mathematical Monthly, vol. 83, no. 4, pp. 261-263, 1976.

[2] S. L. Singh, C. Bhatnagar, and S. N. Mishra, "Stability of Jungcktype iterative procedures," International Journal of Mathematics and Mathematical Sciences, no. 19, pp. 3035-3043, 2005.

[3] M. O. Olatinwo, "Some stability and strong convergence results for the Jungck-Ishikawa iteration process," Creative Mathematics and Informatics, vol. 17, pp. 33-42, 2008.

[4] A. O. Bosede, "Strong convergence results for the Jungck-Ishikawa and Jungck-Mann iteration processes," Bulletin of Mathematical Analysis and Applications, vol. 2, no. 3, pp. 65-73, 2010.
[5] J. O. Olaleru and H. Akewe, "On multistep iterative scheme for approximating the common fixed points of contractive-like operators," International Journal of Mathematics and Mathematical Sciences, vol. 2010, Article ID 530964, 11 pages, 2010.

[6] M. O. Olatinwo, "A generalization of some convergence results using a Jungck-Noor three-step iteration process in arbitrary Banach space," Polytechnica Posnaniensis, no. 40, pp. 37-43, 2008.

[7] R. Chugh and V. Kumar, "Strong Convergence and Stability results for Jungck-SP iterative scheme," International Journal of Computer Applications, vol. 36, no. 12, 2011.

[8] W. Phuengrattana and S. Suantai, "On the rate of convergence of Mann, Ishikawa, Noor and SP-iterations for continuous functions on an arbitrary interval," Journal of Computational and Applied Mathematics, vol. 235, no. 9, pp. 3006-3014, 2011.

[9] M. A. Noor, "New approximation schemes for general variational inequalities," Journal of Mathematical Analysis and Applications, vol. 251, no. 1, pp. 217-229, 2000.

[10] S. Ishikawa, "Fixed points by a new iteration method," Proceedings of the American Mathematical Society, vol. 44, no. 1, pp. 147$150,1974$.

[11] W. R. Mann, "Mean value methods in iteration," Proceedings of the American Mathematical Society, vol. 4, pp. 506-510, 1953.

[12] R. P. Agarwal, D. O’Regan, and D. R. Sahu, "Iterative construction of fixed points of nearly asymptotically nonexpansive mappings," Journal of Nonlinear and Convex Analysis, vol. 8, no. 1, pp. 61-79, 2007.

[13] D. R. Sahu and A. Petruşel, "Strong convergence of iterative methods by strictly pseudocontractive mappings in Banach spaces," Nonlinear Analysis: Theory, Methods \& Applications, vol. 74, no. 17, pp. 6012-6023, 2011.

[14] V. Berinde, "Picard iteration converges faster than Mann iteration for a class of quasi-contractive operators," Fixed Point Theory and Applications, no. 2, pp. 97-105, 2004.

[15] Y. Qing and B. E. Rhoades, "Comments on the rate of convergence between Mann and Ishikawa iterations applied to Zamfirescu operators," Fixed Point Theory and Applications, vol. 2008, Article ID 387504, 3 pages, 2008.

[16] N. Hussain, G. Jungck, and M. A. Khamsi, "Nonexpansive retracts and weak compatible pairs in metric spaces," Fixed Point Theory and Applications, vol. 2012, article 100, 2012.

[17] G. Jungck and N. Hussain, "Compatible maps and invariant approximations," Journal of Mathematical Analysis and Applications, vol. 325, no. 2, pp. 1003-1012, 2007.

[18] V. Berinde, "On the convergence of the Ishikawa iteration in the class of quasi contractive operators," Acta Mathematica Universitatis Comenianae, vol. 73, no. 1, pp. 119-126, 2004.

[19] R. Chugh and V. Kumar, "Convergence of SP iterative scheme with mixed errors for accretive Lipschitzian and strongly accretive Lipschitzian operators in Banach space," International Journal of Computer Mathematics, vol. 2013, 17 pages, 2013.

[20] N. Hussain, A. Rafiq, B. Damjanović, and R. Lazović, "On rate of convergence of various iterative schemes," Fixed Point Theory and Applications, vol. 45, 6 pages, 2011.

[21] B. E. Rhoades, "Comments on two fixed point iteration methods," Journal of Mathematical Analysis and Applications, vol. 56, no. 3, pp. 741-750, 1976.

[22] S. L. Singh, "A new approach in numerical praxis," Progress of Mathematics, vol. 32, no. 2, pp. 75-89, 1998.

[23] N. Hussain, R. Chugh, V. Kumar, and A. Rafiq, "On the rate of convergence of Kirk-type iterative schemes," Journal of Applied Mathematics, Article ID 526503, 22 pages, 2012. 
[24] N. Hussain, A. Rafiq, L. B. Ciric, and S. Al-Mezel, "Almost stability of the Mann type iteration method with error term involving strictly hemicontractive mappings in smooth Banach spaces," Journal of Inequalities and Applications, vol. 2012, article 207, 2012.

[25] N. Hussain, A. Rafiq, and L. B. Ciric, "Stability of the Ishikawa iteration scheme with errors for two strictly hemicontractive operators in Banach spaces," Fixed Point Theory and Applications, vol. 2012, article 160, 2012.

[26] S. H. Khan, A. Rafiq, and N. Hussain, "A three-step iterative scheme for solving nonlinear $\phi$-strongly accretive operator equations in Banach spaces," Fixed Point Theory and Applications, vol. 2012, article 149, 2012.

[27] Y. Song and X. Liu, "Convergence comparison of several iteration algorithms for the common fixed point problems," Fixed Point Theory and Applications, vol. 2009, Article ID 824374, 13 pages, 2009.

[28] M. F. Barnsley, Fractals Everywhere, Academic Press Professional, Boston, Mass, USA, 2nd edition, 1993. 


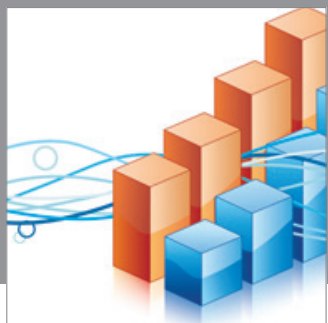

Advances in

Operations Research

mansans

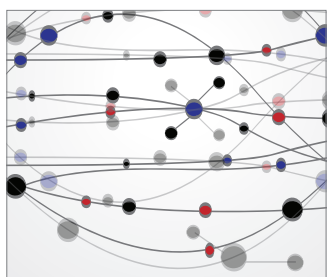

The Scientific World Journal
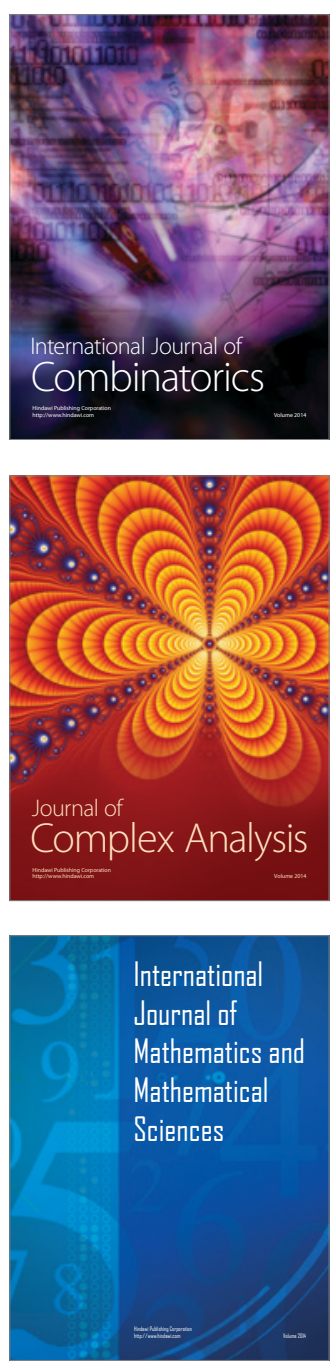
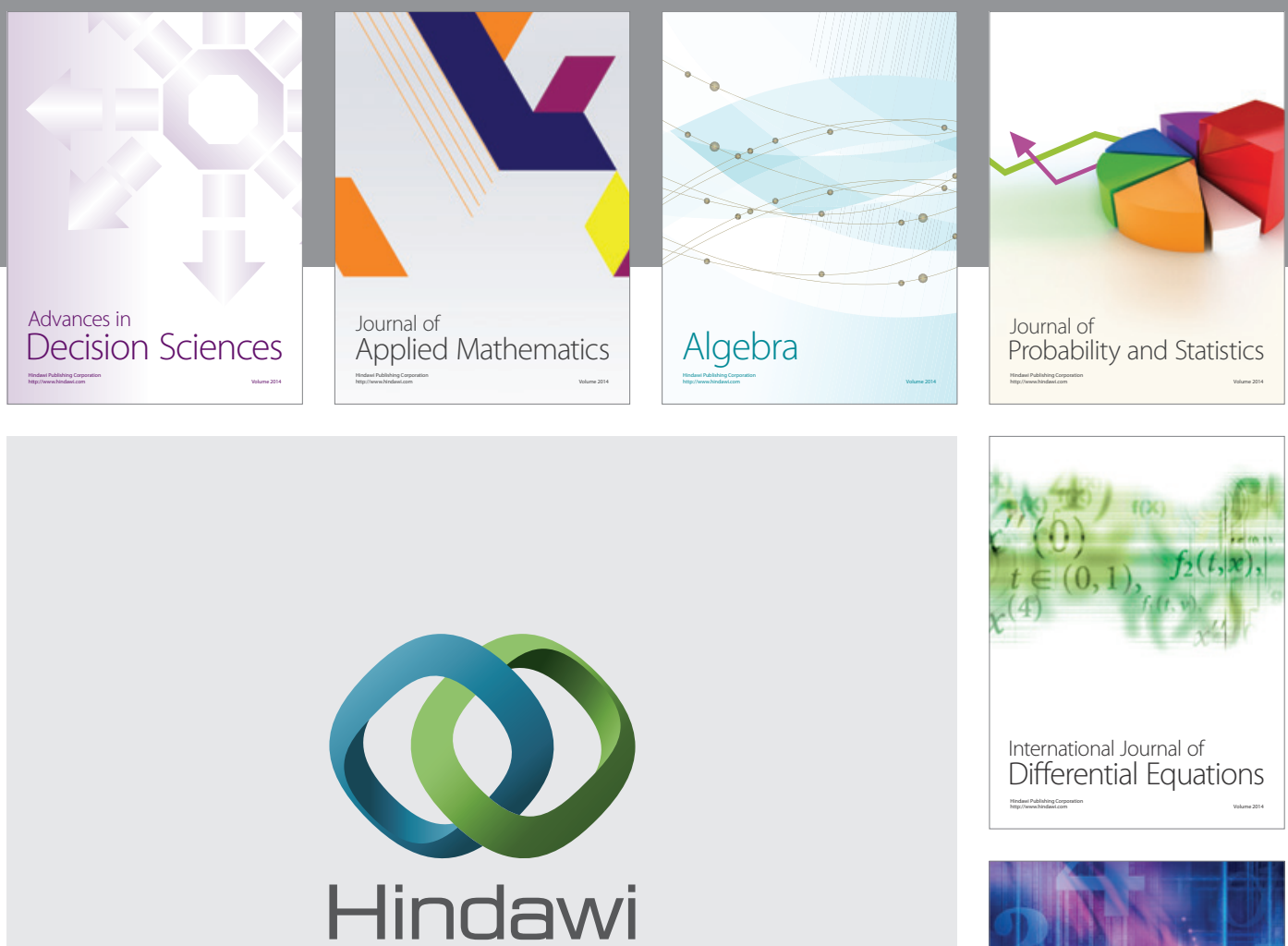

Submit your manuscripts at http://www.hindawi.com
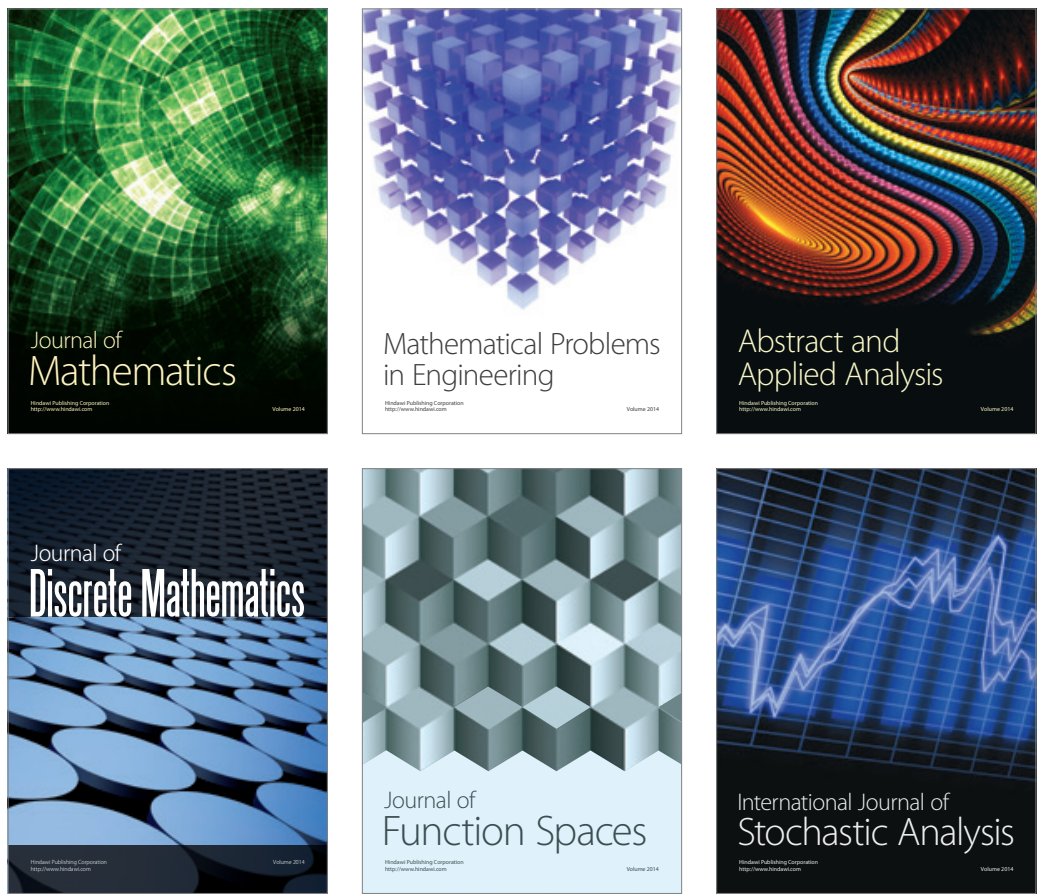

Journal of

Function Spaces

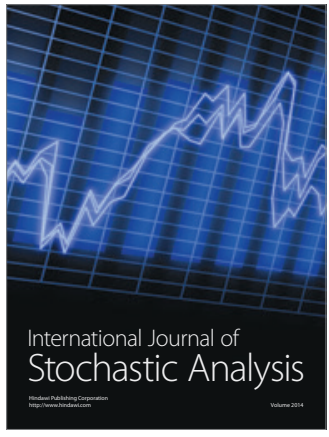

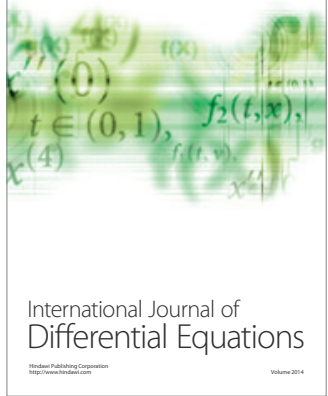
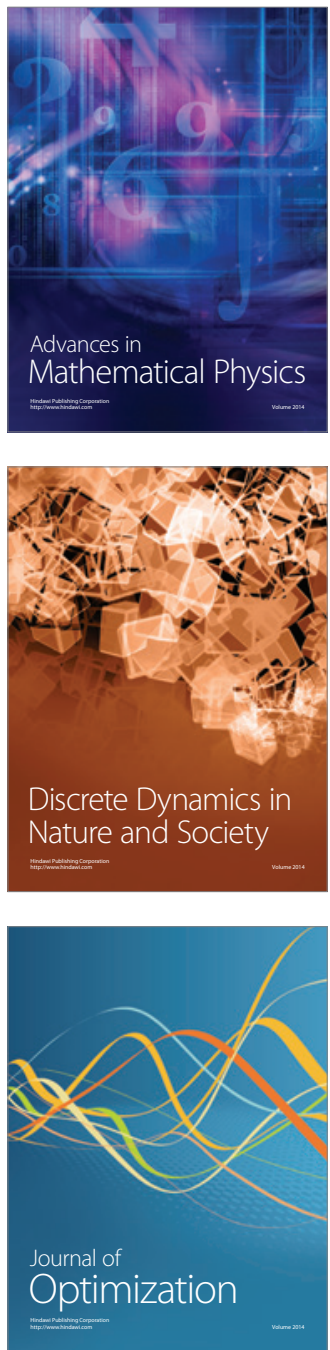